\title{
Unusual features of pomoviral RNA movement
}

\section{Lesley Torrance $^{1}$ *, Kathryn M. Wright ${ }^{1}$, François Crutzen ${ }^{2}$, Graham H. Cowan ${ }^{1}$, Nina I. Lukhovitskaya ${ }^{3}$, Claude Bragard ${ }^{2}$ and Eugene I. Savenkov ${ }^{3}$}

${ }^{1}$ Cell and Molecular Sciences, The James Hutton Institute, Dundee, UK

${ }^{2}$ Applied Microbiology-Phytopathology, Earth and Life Institute, Université Catholique de Louvain, Louvain-la-Neuve, Belgium

${ }^{3}$ Department of Plant Biology and Forest Genetics, Uppsala BioCentre, Swedish University of Agricultural Sciences, Uppsala, Sweden

\section{Edited by:}

Vitaly Citovsky, State University of

New York at Stony Brook, USA

Reviewed by:

Michael Taliansky, The James Hutton Institute, UK

Valerian V. Dolja, Oregon State

University, USA

*Correspondence:

Lesley Torrance, Cell and Molecular Sciences, The James Hutton Institute, Invergowrie, Dundee, DD2 5DA,

Scotland, UK.

e-mail: lesley.torrance@hutton.ac.uk
Potato mop-top pomovirus (PMTV) is one of a few viruses that can move systemically in plants in the absence of the capsid protein (CP). Pomoviruses encode the triple gene block genetic module of movement proteins (TGB 1,2, and 3) and recent research suggests that PMTV RNA is transported either as ribonucleoprotein (RNP) complexes containing TGB1 or encapsidated in virions containing TGB1. Furthermore, there are different requirements for local or systemic (long-distance) movement. Research suggests that nucleolar passage of TGB1 may be important for the long-distance movement of both RNP and virions. Moreover, and uniquely, the long-distance movement of the CP-encoding RNA requires expression of both major and minor CP subunits and is inhibited when only the major CP sub unit is expressed. This paper reviews pomovirus research and presents a current model for RNA movement.

Keywords: Pomovirus, PMTV, BVQ, BSBV, nucleus, nucleolus, microtubules, TGB

\section{INTRODUCTION}

The genus Pomovirus is classified in the family Virgaviridae and comprises Potato mop-top virus (PMTV), the type species, Beet soil-borne virus (BSBV), Beet virus Q (BVQ), and Broad bean necrosis virus (Koenig and Lesemann, 2005; Adams et al., 2009). These viruses have tubular rod-shaped particles containing three species of positive-sense, single-stranded RNA. The genome is organized such that replicase, movement proteins, and capsid protein $(\mathrm{CP})$ are encoded on separate species of RNA. Pomoviruses encode a conserved genetic module of movement proteins called the triple gene block (TGB) which comprises three overlapping open reading frames directing synthesis of proteins named TGB1, TGB2, and TGB3 according to their position within TGB. The expression of TGB is strictly regulated to control virus movement. Three groups of TGB-encoding viruses have been distinguished (Verchot-Lubicz et al., 2010) that show some variation in TGB mode of action and detailed mechanisms of transport but in general it is thought that TGB1 (an RNA-binding protein) interacts with viral RNA and possibly other viral or plant factors to form a ribonucleoprotein (RNP) complex and the integral membrane proteins TGB2 and TGB3 facilitate RNP transport to the periphery of the cell and delivery to plasmodesmata (PD).

Conceptually, the virus movement process has been separated into cell-to-cell movement and long-distance (systemic) movement since access to the vascular system, the plant "super highway" that is required for systemic spread, seems to require different factors (Lough and Lucas, 2006) and specifically entry to the phloem by passage through PD at the companion cell-sieve element boundary appears to constitute a particular barrier (Oparka and Turgeon, 1999). PMTV is one of a few viruses that can move long distance in plants without the need for capsid proteins. We have shown that the $\mathrm{CP}$ and the minor capsid protein (CP-RT, formed by suppression of the $\mathrm{CP}$ amber stop codon to produce a longer polypeptide of $89 \mathrm{kDa}$ ) are dispensable for replication, cell-to-cell movement, and long-distance movement of the RNAs encoding replicase (RNA-Rep) and movement proteins (RNATGB; McGeachy and Barker, 2000; Savenkov et al., 2003). CP-RT was shown to be present at one extremity of the particle (Cowan et al., 1997) and it is known that spontaneous deletions can occur within the central part of the ORF including deletion of a domain that is essential for transmission by the natural vector Spongospora subterranea (Reavy et al., 1998; Sandgren et al., 2001).

\section{CELL-TO-CELL MOVEMENT}

The localizations of PMTV movement proteins TGB2 and TGB3 were studied by imaging living cells in which the TGB were expressed as fusions with fluorescent proteins using confocal laser scanning microscopy (CLSM; Cowan et al., 2002; Zamyatnin et al., 2004; Haupt et al., 2005; Tilsner et al., 2010). The yeast two-hybrid system and bimolecular fluorescence complementation (BiFC) were also used to examine their interactions and topology in cellular membranes (Cowan et al., 2002; Zamyatnin et al., 2006; Tilsner et al., 2010). These experiments showed that TGB2 and TGB3 displayed homologous and heterologous interactions and that they co-localized in the cortical endoplasmic reticulum and later in expression targeted PD and small motile vesicles. The TGB3 contained the PD targeting signal. When TGB2 and TGB3 were co-expressed from a bicistronic construct in cells expressing GFP-TGB1 the TGB1 was localized to PD and moved into adjacent cells, whereas TGB1 was present in the cytoplasm and nucleus and did not spread to neighboring cells when expressed alone (Wright et al., 2010). TGB2 and TGB3 did not move from cell-to-cell and their role in movement appears to be the intracellular transport of RNP to PD (Zamyatnin et al., 2004; Haupt et al., 2005; Tilsner et al., 2010; Wright et al., 2010). 


\section{LONG-DISTANCE MOVEMENT}

As stated previously, PMTV is one of a small group of viruses that can move long distance in plants in the absence of CP. This is somewhat unexpected since PMTV is transmitted in nature by a soil-borne vector and the CP-RT contains a domain essential for transmission, therefore, separation of RNA-CP from the infection would lead to a "dead end" in terms of virus spread. In experiments to examine the role of $\mathrm{CP}$ and CP-RT in RNA movement a series of mutant RNA-CP clones containing deletions in the $\mathrm{C}$ terminus of CP-RT were prepared (Torrance et al., 2009). RNA transcripts of these were inoculated to Nicotiana benthamiana together with transcripts of the other two RNAs and leaves were analyzed by Western and Northern blots for local and systemic infection. The results revealed that most deletions prevented the long-distance movement of RNA-CP to upper noninoculated leaves but did not impair the movement of the other two RNA species. However, all three RNA species and CP were detected in the inoculated leaves showing that cell-to-cell movement was not affected. Interestingly, a mutant clone carrying a deletion in a region that has been identified as a recombination hot spot also supported the long-distance movement of RNA-CP (Torrance et al., 2009). To identify the domain involved, further C-terminal deletion mutants of CP-RT were prepared as well as mutants that were designed to prevent any protein expression at all (no protein) or to express either CP alone (CP only) or suppress $\mathrm{CP}$ production so that only CP-RT is produced. Experiments with these mutants showed that in the absence of $\mathrm{CP}$ (no protein or only CP-RT), all three RNA species were detected in inoculated and upper non-inoculated leaves. However, with either CP only or C-terminal truncated CP-RT mutants, RNA-Rep, and RNA-TGB were detected in the upper leaves by Northern blots but RNA-CP was not detected. A domain between 2300 and 2730 nt near the $C$ terminus was shown to be required for long-distance movement of RNA-CP. The mutations did not affect virus particle formation as particles were observed by electron microscopy of negatively stained extracts from leaves infected with mutants expressing only $\mathrm{CP}$ and some of the CP-RT C-terminal deletion mutants (Torrance et al., 2009).

These experiments indicate different requirements for RNA movement and we conclude that PMTV RNA moves in two different forms. When no CP is present (or not expressed) then all three RNAs can form RNP complexes presumably with TGB1 and possibly other virus or plant components to move long distance. However, when the capsid proteins are expressed the RNAs become encapsidated and they also move long distance as particles. Experiments have shown that particles formed by $\mathrm{CP}$ alone (i.e., without CP-RT) cannot move out of the inoculated leaf and the CP-RT has been detected at one extremity of virions. Taken together with the CP-RT deletion mutant analysis described above, these findings suggest that the CP-RT mediates long-distance movement through a domain at the $\mathrm{C}$ terminus when incorporated into the virion.

This poses the question of how CP-RT can mediate longdistance RNA movement. Yeast two-hybrid experiments have shown that CP-RT interacts with itself and with TGB1 and CP, however, CP does not interact with TGB1 (Torrance et al., 2009). Further experiments revealed that the C-terminal portion of
CP-RT was necessary for the interaction with TGB1 and a positive interaction was correlated with long-distance movement of RNACP. Enzyme-linked immunosorbent assays of leaves infected with wild type and mutant viruses suggest that TGB1 is also a component of movement competent virions. Therefore, the results are compatible with long-distance movement of virions that contain CP-RT and TGB1 at the tip. In this aspect, PMTV particles differ from those potato virus $\mathrm{X}$ (another TGB containing virus) where TGB1 is associated with one extremity but this interaction is thought to promote particle instability and RNA translation (Karpova et al., 2006; Atabekov et al., 2007). The role in virus movement of supplementary proteins incorporated at the tip of filamentous virus particles was first shown for beet yellows closterovirus (Peremyslov et al., 2004) and has also been suggested for potato potyviruses (Torrance et al., 2006). It seems that they confer polarity to helically constructed particles probably for directed translocation through the PD pore; for closteroand potyviruses the proteins are located at the extremity containing the $5^{\prime}$ end of the RNA and we think this is also true for PMTV (Cowan et al., 1997; Torrance et al., 2009). Notably, three genera of viruses with terminal structures (poty-, potex-, and closteroviruses) have flexuous filamentous virions whereas, PMTV is the only example of a virus with rigid rod-shaped virions so far. The intricate architecture of these virions suggests a new paradigm in which filamentous and rigid virions are not just containers with helical symmetry, but dynamic entities, which incorporate proteins needed for efficient virus transmission, cell-to-cell, and long-distance movement.

Interestingly, and uniquely, restriction of movement by CP-RT mutants only applies to the long-distance movement of RNA-CP, the other two RNAs can move long-distance in the presence of the CP or mutant CP-RT proteins and all three RNAs can move cell-to-cell. Therefore, our current hypothesis is that TGB1 tipped particles or a RNP comprising TGB1 are required for entry to/or exit from the vasculature.

Another question that arises is why only the RNA-CP is inhibited by these mutations. Comparison of the nucleotide sequence of PMTV RNAs reveals that while the $3^{\prime}$ UTR regions are conserved and form tRNA-like structures, there are differences at the $5^{\prime}$ ends. There is good conservation between the first 42 nucleotides (nt) of RNA-Rep and RNA-TGB but a much weaker relationship with RNA-CP (Savenkov et al., 1999) and the predicted structures of the $5^{\prime}$ ends are different (Figure 1). It is possible that this region contains an element that confers a stronger affinity for CP binding than the other RNA species possibly out-competing them for available $\mathrm{CP}$ and allowing them to escape from the cell before high levels of $\mathrm{CP}$ accumulate, or that this region favors the binding of CP over TGB1 and inhibits the formation of RNPs containing TGB1.

It has been shown previously that other rod-shaped TGB containing viruses (Beet necrotic yellow vein virus, BNYVV; Peanut clump virus, PCV; Barley stripe mosaic virus, BSMV; and BSBV) can move cell-to-cell in the absence of CP, however, only BSMV and PMTV can move long distance in the absence of CP. Moreover, in all these viruses except BSBV and PMTV, the CP is encoded on the same RNA species as the TGB and so the gene cannot be lost from the population. Purified BSMV RNP complexes contained 


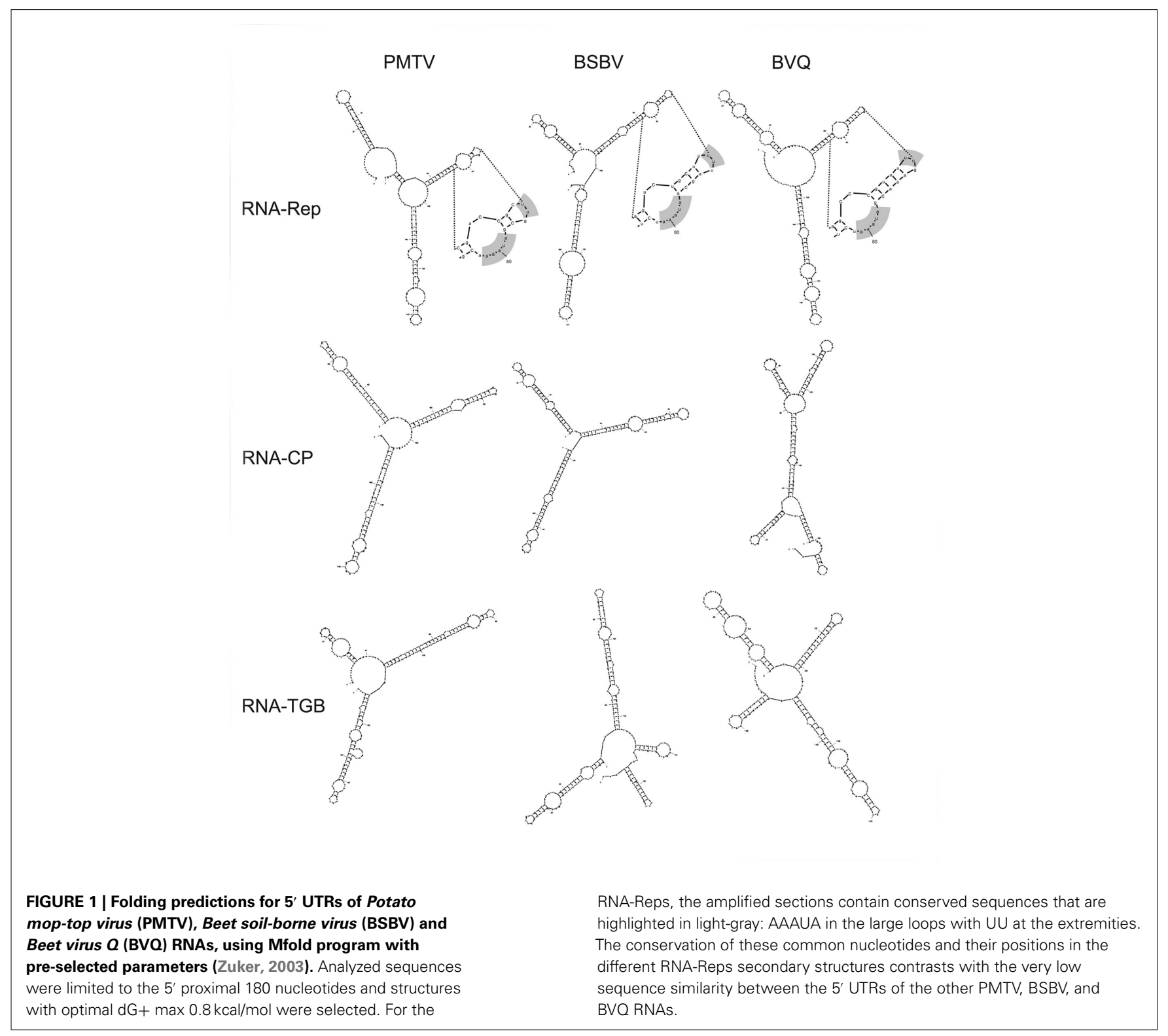

only TGB1 but not other virus proteins which suggests that the movement form of BSMV is a RNP (Jackson et al., 2009).

\section{BEET POMOVIRUS TERMINAL UTRS}

Similar to PMTV and other viruses of the Virgaviridae (Goodwin and Dreher, 1998; Dreher, 2009; Dieryck et al., 2010), the 3' extremities of BSBV and BVQ RNAs fold into tRNA-like structures that are highly conserved with only seven nucleotide variations in the terminal $46 \mathrm{nt}$. On the other hand, poor sequence similarity is observed inter- and even intra-species for the $5^{\prime}$ UTRs (Koenig et al., 1998). Furthermore, unlike PMTV and other Virgaviridae, the beet pomovirus RNAs do not always contain the canonical GUA $(U)_{n}$ motif at their $5^{\prime}$ ends. BSBV RNAs- 2 and -3 begin with GGU $(A)_{2}(\mathrm{U})_{4}$ and GGUA(U) ${ }_{9}$, and BVQ RNAs- 1 and -2 with $\mathrm{AU}(\mathrm{A})_{2}(\mathrm{U})_{5}$ and $\mathrm{GU}(\mathrm{A})_{4}(\mathrm{U})_{2}$, respectively. Since it is expected that BSBV and BVQ 5' UTRs contain elements involved in either viral replication, movement or encapsidation, these differences, similar to PMTV, may reflect changes in RNA structure that affects interactions with other factors (Figure 1).

\section{BVO LONG-DISTANCE MOVEMENT IN C. QUINOA MAY BE RNA-CP DEPENDENT}

Beet soil-borne virus and BVQ induce local lesions on Chenopodium quinoa leaves inoculated with sap from infected plants (Henry et al., 1986; Koenig et al., 1998) or RNA transcripts generated from full-length cDNA clones (Crutzen et al., 2009b; Crutzen and Bragard, unpublished data). No long-distance movement of BSBV or BVQ has been reported in this host.

Nevertheless, recent advances in the study of BVQ by reverse genetics suggest that BVQ RNAs can move long distance in C. quinoa (Figures 2A,B). This contradiction concerning BVQ long-distance movement could be explained by the possible 
involvement of the BVQ CP-RT in long-distance movement, as the isolate originally described was shown to carry a truncated CPRT encoding sequence (Koenig et al., 1998; Crutzen et al., 2009a). This hypothesis is also supported by the lack of systemic symptoms on C. quinoa leaves when the CP and CP-RT encoding RNA-2 is omitted (Crutzen and Bragard, unpublished data).

\section{THE ENIGMATIC ROLE OF THE NUCLEUS}

In addition to localization in the PD, PMTV YFP-TGB1 when expressed with RNA-Rep, in the presence or absence of RNA-CP, was observed in the nucleoplasm, nucleolus (Figure 2C), and was associated with microtubules (MT, Wright et al., 2010). Makarov et al. (2009) reported that the TGB1 proteins of the hordei-, pomo-, and peclu-viruses BSMV, Poa semilatent virus (PSLV), PMTV, and $\mathrm{PCV}$, contain an unstructured region at the $\mathrm{N}$ terminus called the NTD domain that binds ss and dsRNA. There are two basic amino acid clusters that are typical of RNA-binding motifs in the NTD of PSLV (Kalinina et al., 2001) and mutation in these domains of PSLV TGB1 abolished virus long distance but not cell-to-cell movement of a chimeric BSMV carrying the mutated TGB1 (Kalinina et al., 2001). PMTV TGB1 also contains putative nuclear and nucleolar localization signals in this domain and deletion of $84 \mathrm{~N}$-terminal amino acids comprising most of the NTD also abolished long distance but not cell-to-cell movement of all three RNA species as judged by Northern blotting. When this deletion was introduced to the reporter clone PMTV. YFPTGB1, labeling of MT and the nucleolus was abolished but the fusion protein still accumulated in the nucleus (Figure 2D). The $\mathrm{N}$-terminal deletion in TGB1 did not affect interactions with CPRT and TGB1 in the yeast two-hybrid assay indicating that the $\mathrm{N}$ terminus is not involved in these interactions (Wright et al., 2010). Furthermore, GFP-fusions to the $\mathrm{N}$ terminus of TGB1 in the reporter clone do not affect cell-to-cell movement as fluorescent spreading lesions were observed (Wright et al., 2010) but longdistance movement was prevented. Fusion of the $84 \mathrm{~N}$-terminal amino acids of TGB1 to GFP caused the GFP to accumulate in the nucleolus but not on MT and alanine substitutions of basic residues in this region in the TGB1 fusion protein also abolished nucleolar accumulation of the mutant YFP-TGB1 (unpublished results). Taken together these data indicate that the $\mathrm{N}$ terminus of TGB1 either contains a nucleolar targeting signal or contains a domain that recruits host factor(s) that assists transport into the nucleolus (Wright et al., 2010, and Wright et al., unpublished results).

In conclusion, the $\mathrm{N}$ terminus of TGB1 appears to be important for long-distance movement of viral RNA by an unknown mechanism and such movement is correlated with association of TGB1 with the nucleolus and MT (Figure 2E). So far, we have been unable to separate temporally the TGB1 nucleolar and MT associations to better understand their respective roles. It is not yet clear whether both of these associations are important for RNA movement or whether they have some other function. Other viruses that have a nucleolar phase such as Groundnut rosette virus (GRV; Kim et al., 2007b) have been shown to acquire a host factor, fibrillarin from the nucleolus and fibrillarin is re-localized and incorporated into a RNP that is competent for long-distance movement (Kim et al., 2007a). However, we do not see a similar re-localization of fibrillarin from the nucleolus with PMTV infections (unpublished results).

\section{THE ENIGMATIC ROLE OF THE MICROTUBULES}

The role of the MT network during pomovirus infection remains an intriguing question. Indeed, leaf treatment with MTdepolymerizing drugs does not prevent PMTV cell-to-cell and long-distance movement (Wright et al., 2010). Similar results were also reported for the tobacco mosaic virus movement protein (TMV-MP) which interacts with MT (Gillespie et al., 2002). Moreover, as the viral titers of both PMTV and TMV are not significantly altered upon MT disruption, the MT network seems not to be essential for the virus infection. However, plant viruses must subvert the host cell machinery to access cellular resources needed for infection. Interfering with MT dynamics is one way to suppress the signaling pathways involved in host response to virus infection. Indeed, it has been shown recently that tobacco mutants with reduced MT dynamics can tolerate TMV infection better than wild type plants (Ouko et al., 2010). Moreover, better tolerance of the mutant plants was attributed to decreased TMV cell-to-cell movement accompanied by a decreased association of TMV-MP with PD.

In other systems, autophagy and proteasome degradation involves protein trafficking along MT to the aggresome (Kraft et al., 2010; Wong and Cuervo, 2010). Thus, disturbing the MT dynamics may inhibit trafficking of defense signals. This might help the virus to suppress autophagy and prevent HR induction, because autophagy contributes to hypersensitive cell death through EDS1 signaling (Hofius et al., 2009).

In contrast with TMV-MP PMTV TGB1 does not stabilize the MT network (Wright et al., 2010), which might make pomoviral TGB1 more flexible in terms of interference with MT dynamics. Another important feature of PMTV movement protein TGB1 is its potential association with one terminus of the virus particles through its interaction with CP-RT (Torrance et al., 2009), which in turn is implicated in transmission of the virus by the soil-borne vector S. subterranea (Reavy et al., 1998). One can speculate that by sitting on the very tip of the virus particles TGB1 might be involved in transmission of the virus through interaction with MT of the S. subterranea plasmodium, as was reported for Rice gall dwarf virus (RGDV; Wei et al., 2009). MT appear to facilitate RGDV transport from viroplasms to the cell periphery and subsequent release of viruses from infected vector cells (Wei et al., 2009). Additionally, analysis of PMTV and BVQ CP-RT sequences revealed the presence of two hydrophobic helices with a structure similar to some fusion proteins (Fproteins) encoded by animal viruses, which mediate the fusion of the viral outer membrane with the plasmalemma. We hypothesize that during transmission of the virus from S. subterranea plasmodium to the plant cell TGB1 translocates virus particles to the plasmodium plasma membrane through interaction with MT; CP-RT, on the other hand, facilitates fusion of the plant and plasmodium membranes and subsequent transfer of the virions onto plant cell MT. The hypothesis might be verified by testing whether TGB1 del 84 mutant, which lacks a domain involved in MT association, could be transmitted by $S$. subterranea. 

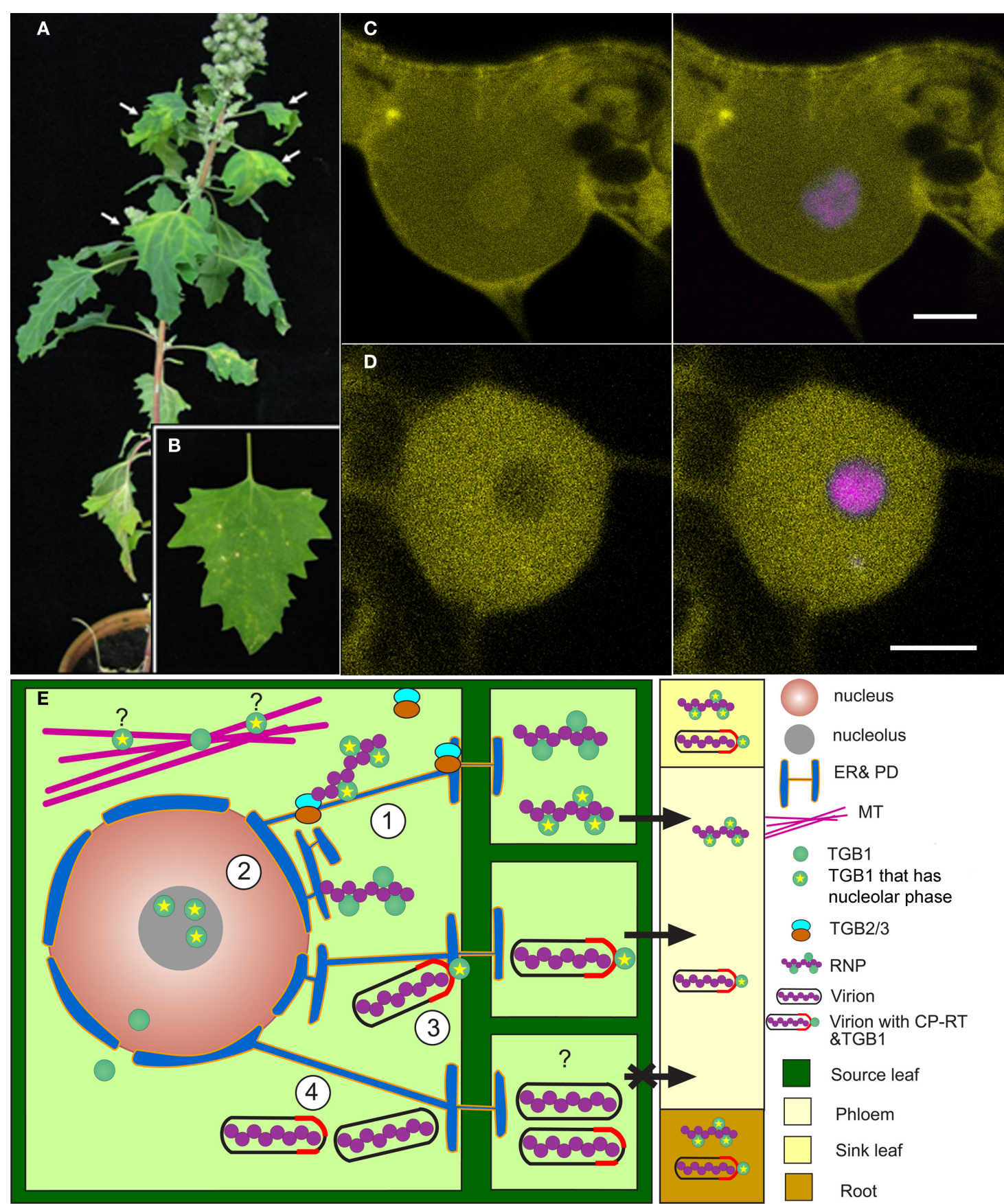

FIGURE 2 | (A,B) Systemic infection of Chenopodium quinoa by BVQ RNA transcripts. (A) Upper non-inoculated leaves show chlorosis and necrosis and (B) local lesions induced on inoculated leaves. (C,D) Single confocal microscope sections showing nuclear and nucleolar accumulation of YFP-TGB1 expressed from the PMTV reporter clone. [(C) left panel) YFP-TGB1 and (D): YFP-del84-TGB1. [(C,D) right panels], co-expression of the respective proteins with monomeric red fluorescent protein-labeled Arabidopsis fibrillarin 2 (magenta) to distinguish the nucleolus. Scale bar $=5 \mu \mathrm{m}$. (E) Model of PMTV RNA movement. (1) Viral RNP complexes are transported intra-cellularly by TGB2 and TGB3 on the endoplasmic reticulum-actin network to the $\mathrm{PD}$. (2) TGB1 enters the nucleolus where it either acquires a host factor or is modified in some way, or acts to modify the host to facilitate long-distance movement of RNP or (3), tipped virions in the vasculature. (4) Virions that do not contain CP-RT or that contain mutant CP-RT that does not interact with TGB1 are not competent for long-distance movement.

\section{FUTURE WORK}

Current research is focused on investigating whether BSBV and BVQ can also move long-distance independently of CP and whether long-distance movement can be recovered by complementation by inoculation of BVQ RNA-2 together with the original BVQ isolate which does not infect C. quinoa systemically (R. 
Koenig, personal communication, Crutzen et al., 2009a). We have shown by BiFC that PMTV TGB1 interacts in vivo with the plant nuclear transport factor importin $\alpha$ (unpublished results) and knockdown of importin expression should provide some clues on the role of the nucleolar phase of TGB1 in pomovirus movement. The TGB1 protein seems to be the main determinant needed for both viral cell-to-cell (forming RNP complexes) and systemic movement (as a tip of polar virions). Thus, identification of the host proteins interacting with TGB1 will be of key importance to understanding the mechanism of viral RNA trafficking in plants. Screening of plant cDNA libraries using TGB1 as the bait should

\section{REFERENCES}

Adams, M., Antoniw, J., and Kreuze, J. (2009). Virgaviridae: a new family of rod-shaped plant viruses. Arch. Virol. 154, 1967-1972.

Atabekov, J., Dobrov, E., Karpova, O., and Rodionova, N. (2007). Potato virus $\mathrm{X}$ : structure, disassembly and reconstitution. Mol. Plant Pathol. 8, 667-675.

Cowan, G. H., Lioliopoulou, F., Ziegler, A., and Torrance, L. (2002). Subcellular localisation, protein interactions, and RNA binding of Potato mop-top virus triple gene block proteins. Virology 298, 106-115.

Cowan, G. H., Torrance, L., and Reavy, B. (1997). Detection of potato moptop virus capsid readthrough protein in virus particles. J. Gen. Virol. 78, 1779-1783.

Crutzen, F., Kreit, M., and Bragard, C. (2009a). The beet virus Q coat protein readthrough domain is longer than previously reported, with two transmembrane domains. J. Gen. Virol. 90, 754-758.

Crutzen, F., Mehrvar, M., Gilmer, D., and Bragard, C. (2009b). A fulllength infectious clone of beet soilborne virus indicates the dispensability of the RNA-2 for virus survival in planta and symptom expression on Chenopodium quinoa leaves. J. Gen. Virol. 90, 3051-3056.

Dieryck, B., Delfosse, P., Reddy, A. S., and Bragard, C. (2010). Targeting highly conserved $3^{\prime}$ - untranslated region of pecluviruses for sensitive broad-spectrum detection and quantitation by RT-PCR and assessment of phylogenetic relationships. J. Virol. Methods 169, 385-390.

Dreher, T. W. (2009). Role of tRNA-like structures in controlling plant virus replication. Virus Res. 139, 217-229.

Gillespie, T., Boevink, P., Haupt, S., Roberts, A. G., Toth, R., Valentine, T. A., Chapman, S., and Oparka, K. J. (2002). Functional analysis of a DNA-shuffled movement protein reveals that microtubules are dispensable for the cell-to-cell movement of Tobacco mosaic virus. Plant Cell 14, 1207-1222.
Goodwin, J. B., and Dreher, T. W. (1998). Transfer RNA mimicry in a new group of positive-strand RNA plant viruses, the Furoviruses: differential aminoacylation between the RNA components of one genome. Virology 246, 170-178.

Haupt, S., Cowan, G. H., Ziegler, A., Roberts, A. G., Oparka, K. J., and Torrance, L. (2005). Two plant-viral movement proteins traffic in the endocytic recycling pathway. Plant Cell 17, 164-181.

Henry, C. M., Jones, R. A. C., and Coutts, R. H. A. (1986). Occurrence of a soilborne virus of sugar beet in England. Plant Pathol. 35, 585-591.

Hofius, D., Schultz-Larsen, T., Joensen, J., Tsitsigiannis, D. I., Petersen, N. H. T., Mattsson, O., Jorgensen, L. B., Jones, J. D. G., Mundy, J., and Petersen, M. (2009). Autophagic components contribute to hypersensitive cell death in Arabidopsis. Cell 137, 773-783.

Jackson, A. O., Lim, H. S., Bragg, J., Ganesan, U., and Lee, M. Y. (2009). Hordeivirus replication, movement, and pathogenesis. Annu. Rev. Phytopathol. 47, 385-422.

Kalinina, N. O., Rakitina, D. A., Yelina, N. E., Zamyatnin, A. A., Stroganova, T. A., Klinov, D. V., Prokhorov, V. V., zov, S. Y. (2001). RNA-binding properties of the 63-kDa protein encoded by the triple gene block of poa semilatent Hordeivirus. J. Gen. Virol. 82, 2569-2578.

Karpova, O. V., Zayakina, O. V., Arkhipenko, M. V., Sheval, E. V., Kiselyova, O. I., Poljakov, V. Y., Yaminsky, I. V., Rodionova, N. P., and Atabekov, J. G. (2006). Potato virus X RNA-mediated assembly of singletailed ternary 'coat protein-RNAmovement protein' complexes. J. Gen. Virol. 87, 2731-2740.

Kim, S. H., MacFarlane, S., Kalinina, N. O., Rakitina, D. V., Ryabov, E. V., Gillespie, T., Haupt, S., Brown, J. W. S., and Taliansky, M. (2007a). Interaction of a plant virus-encoded protein with the major nucleolar protein Ustinova, S. V., Chernov, B. K., Schiemann, J., Solovyev, A. G., and Moro-

shed light on TGB1-interacting host factors and work is ongoing to identify such host proteins.

\section{ACKNOWLEDGMENTS}

The work of L. Torrance, K. M. Wright, and G. H. Cowan is funded by the Scottish Government's Rural and Environment Science and Analytical Services (RESAS) Division. The research of N. I. Lukhovitskaya and E. I. Savenkov is funded by the Swedish Research Council for Environment, Agricultural Sciences and Spatial Planning (Formas, grants 2007-256; 2008-1047; 2009-1979).

fibrillarin is required for systemic virus infection. Proc. Natl. Acad. Sci. U.S.A. 104, 11115-11120.

Kim, S. H., Ryabov, E. V., Kalinina, N. O., Rakitina, D. V., Gillespie, T., MacFarlane, S. A., Haupt, S., Brown, J. W. S., and Talianksy, M. E. (2007b) Cajal bodies and the nucleolus are required for a plant virus systemic infection. EMBO J. 26, 2169-2179.

Koenig, R., and Lesemann, D. E. (2005). "Genus Pomovirus," in Virus Taxonomy. Eighth Report of the International Committee on Taxonomy of Viruses, eds C. M. Fauquet, M. A. Mayo, J. Maniloff, U. Desselberger, and L. A. Ball (San Diego, CA: Elsevier/Academic Press), 1033-1038.

Koenig, R., Pleij, C. W., Beier, C., and Commandeur, U. (1998). Genome properties of beet virus Q, a new furo-like virus from sugarbeet, determined from unpurified virus. $J$. Gen. Virol. 79, 2027-2036.

Kraft, C., Peter, M., and Hofmann, K. (2010). Selective autophagy: ubiquitin-mediated recognition and beyond. Nat. Cell Biol. 12, 836-841.

Lough, T. J., and Lucas, W. J. (2006). Integrative plant biology: role of phloem long-distance macromolecular trafficking. Annu. Rev. Plant Biol. 57, 203-232.

Makarov, V. V., Rybakova, E., Efimov, A. V., Dobrov, E., Serebryakova, M. V., Solovyev, A., Yaminsky, I. V., Taliansky, M., Morozov, S. Y., and Kalinina, N. (2009). Domain organization of the N-terminal portion of Hordeivirus movement protein TGBp1. J. Gen. Virol. 90, 3022-3032.

McGeachy, K. D., and Barker, H. (2000). Potato mop-top virus RNA can move long distance in the absence of coat protein: evidence from resistant, transgenic plants. Mol. Plant Microbe Interact. 13, 125-128.

Oparka, K. J., and Turgeon, R. (1999). Sieve elements and companion cells - traffic control centers of the phloem. Plant Cell 11, 739-750.

Ouko, M. O., Sambade, A., Brandner, K. Niehl, A., Pena, E., Ahad, A., Heinlein, M., and Nick, P. (2010). Tobacco mutants with reduced microtubule dynamics are less susceptible to TMV. Plant J. 62, 829-839.

Peremyslov, V. V., Andreev, I. A., Prokhnevsky, A. I., Duncan, G. H., Taliansky, M. E., and Dolja, V. V. (2004). Complex molecular architecture of beet yellows virus particles. Proc. Natl. Acad. Sci. U.S.A. 101, 5030-5035

Reavy, B., Arif, M., Cowan, G. H. and Torrance, L. (1998). Association of sequences in the coat protein/readthrough domain of potato mop-top virus with transmission by Spongospora subterranea. J. Gen. Virol. 79, 2343-2347.

Sandgren, M., Savenkov, E. I., and Valkonen, J. P. T. (2001). The readthrough region of potato moptop virus (PMTV) coat protein encoding RNA, the second largest RNA of PMTV genome, undergoes structural changes in naturally infected and experimentally inoculated plants. Arch. Virol. 146, 467-477.

Savenkov, E. I., Germundsson, A., Zamyatnin, A. A. Jr., Sandgren, M., and Valkonen, J. P. T. (2003). Potato mop-top virus: the coat proteinencoding RNA and the gene for cysteine-rich protein are dispensable for systemic virus movement in Nicotiana benthamiana. J. Gen. Virol. 84, 1001-1005.

Savenkov, E. I., Sandgren, M., and Valkonen, J. P. T. (1999). Complete sequence of RNA 1 and the presence of tRNA-like structures in all RNAs of potato mop-top virus, genus Pomovirus. J. Gen. Virol. 80, 2779-2784.

Tilsner, J., Cowan, G. H., Roberts, A. G., Chapman, S. N., Ziegler, A., Savenkov, E., and Torrance, L. (2010). Plasmodesmal targeting and intercellular movement of potato mop-top Pomovirus is mediated by a membrane anchored tyrosine-based motif on the lumenal side of the endoplasmic reticulum and the Cterminal transmembrane domain in the TGB3 movement protein. Virology 402, 41-51. 
Torrance et al.

Pomoviral RNA movement

Torrance, L., Andreev, I. A., GabrenaiteVerhovskaya, R., Cowan, G., Mäkinon, K., and Taliansky, M. E. (2006). An unusual structure at one end of potato potyvirus particles. J. Mol. Biol. 357, 1-8.

Torrance, L., Lukhovitskaya, N. I., Schepetilnikov, M. V., Gowan, G. H., Ziegler, A., and Savenkov, E. I. (2009). Unusual long-distance movement strategies of potato moptop virus RNA in Nicotiana benthamiana. Mol. Plant Microbe Interact. 22, 381-390.

Verchot-Lubicz, J., Torrance, L., Solovyev, A. G., Morozov, S. Y., Jackson, A. O., and Wilmer, D. (2010). Varied movement stategives employed by triple gene block-encoding viruses. Mol. Plant Microbe Interact. 23, 1231-1247.

Wei, T., Uehara-Ichiki, T., Miyazaki, N., Hibino, H., Iwasaki, K., and Omura,
T. (2009). Association of rice gall dwarf virus with microtubules is necessary for viral release from cubtoured insect vector cells. J. Tirol. 83, 10830-10835.

Wong, E., and Cuervo, A. M. (2010). Integration of clearance mechanisms: the proteasome and autophagy. Cold Spring Hark. Perspect. Biol. 2, a006734.

Wright, K. M., Gowan, G. H., Lukhovitskaya, N. I., Tilsner, J., Roberts, A. G., Savenkov, E. I., and Torrance, L. (2010). The N-terminal domain of PMTV TGB1 movement protein is required for nucleolar localizaion, microtubule association, and long-distance movement. Mol. Plant Microbe Interact. 23, 1486-1497.

Zamyatnin, A. A., Solovyev, A. G., Bozhkov, P. V., Valkonen, J. P. T., Morozov, S. Y., and Savenkov, E. I. (2006). Assessment of the integral membrane protein topology in liveing cells. Plant J. 46, 145-154.

Zamyatnin, A. A., Solovyev, A. G., Savenkov, E. I., Germundsson, A., Sandgren, M., Valkonen, J. P. T., and Morozov, S. Y. (2004). Transient coexpression of individual genes encoded by the triple gene block of potato mop-top virus reveals requirements for TGBp1 trafficking. Mol. Plant Microbe Interact. 17, 921-930.

Zuker, M. (2003). Mfold web server for nucleic acid folding and hybridizaion prediction. Nucleic Acids Res. 31, 3406-3415.

Conflict of Interest Statement: The authors declare that the research was conducted in the absence of any commercial or financial relationships that could be construed as a potential conflict of interest.
Received: 01 November 2011; accepted: 02 December 2011; published online: 22 December 2011.

Citation: Torrance L, Wright KM, Crutzen F, Gowan GH, Lukhovitskaya NI, Bragard C and Savenkov EI (2011) Unusual features of pomoviral RNA movement. Front. Microbic. 2:259. do: 10.3389/fmicb.2011.00259

This article was submitted to Frontiers in Plant-Microbe Interaction, a specialty of Frontiers in Microbiology.

Copyright (c) 2011 Torrance, Wright, Crutzen, Cowan, Lukhovitskaya, Bragard and Savenkov. This is an open-access article distributed under the terms of the Oreactive Commons Attribution Non Commercial License, which permits non-commercial use, distribution, and reproduction in other forums, provided the original authors and source are credited.

www.frontiersin.org

December 2011 | Volume 2 | Article 259 | 7 